\title{
Polyneuropathies associated with high titre antisulphatide antibodies: characteristics of patients with and without serum monoclonal proteins
}

Glenn Lopate, Becky Jo Parks, Jonathan M Goldstein, Woon-Chee Yee, Gerlyn M Friesenhahn, Alan Pestronk

\begin{abstract}
Objectives-Previous studies of small numbers of patients have shown that antisulphatide autoantibodies are associated with polyneuropathies having a prominent sensory component. However, clinical and electrodiagnostic features are variable. The range of clinical and electrodiagnostic findings in 19 patients with polyneuropathies and high titre $(>4500)$ serum IgM antisulphatide antibodies is described, together with testing for serum monoclonal (M) proteins.
\end{abstract}

Methods-About 20000 serum samples that were referred to the clinical laboratory from 1990 to the end of 1994 were screened by enzyme linked immunosorbent assay (ELISA) for specific high titre antisulphatide antibodies. The clinical and electrodiagnostic data in 23 patients with positive results were reviewed. IgM binding to peripheral nerve structures was also evaluated in these patients.

Results-Nineteen patients had predominantly distal, symmetric pansensory loss. Patients with IgM antisulphatide antibodies and no serum $M$ protein usually had clinical syndromes that included: (1) neuropathic pain or dysaesthesiae, (2) no functionally significant weakness, and (3) an axonal neuropathy on electrodiagnostic testing. On immunocytochemical studies serum IgM from the patients without $M$ proteins usually (nine of 10; $90 \%$ bound to peripheral nerve axons, but never to myelin. Patients with antisulphatide antibodies and a serum $M$ protein, usually IgM, were more likely than patients without a serum $M$ protein, to have syndromes with: (1) no pain or dysaesthesiae, (2) motor abnormalities, and (3) a demyelinating polyneuropathy by electrodiagnostic criteria. In immunocytochemical studies serum IgM most often bound to either peripheral nerve myelin or endoneurial structures.

Conclusion-Patients with polyneuropathy and high titre serum IgM antisulphatide antibodies can be classified into subgroups according to the presence or absence of a serum $M$ protein. Patients without an $M$ protein are more likely to have pure sensory syndromes, pain, an axonal neuropathy, and serum IgM binding to axons. Patients with a serum $M$ protein commonly had syndromes with prominent motor involvement, no pain, and a demyelinating neuropathy.

(F Neurol Neurosurg Psychiatry 1997;62:581-585)

Keywords: antisulphatide antibodies; peripheral nerve disease; paraproteinaemia; demyelinating disease; electrodiagnosis; immunocytochemistry

Patients with high titres of serum autoantibodies directed against sulphatide may have polyneuropathy syndromes with a prominent sensory component. ${ }^{1-6}$ However, previous studies on a few patients have shown the clinical and electrodiagnostic features of polyneuropathies associated with antisulphatide antibody to be variable. Motor findings may be disabling or absent. Electrodiagnostic studies show predominant axonal loss in some patients, but mainly demyelinating features in others.

In this study, we examined the clinical syndromes and electrodiagnostic data in a large series of 23 patients, collected over five years, with high enzyme linked immunosorbent assay (ELISA) titres ( $>4500$ ) of serum IgM antisulphatide antibodies. In the 19 patients with polyneuropathies we considered whether the clinical and electrodiagnostic findings correlated with the results of testing for serum $M$ proteins. We also used immunocytochemistry to evaluate the patterns of serum IgM binding to peripheral nerve.

\section{Methods}

PATIENT SELECTION

We reviewed the results of antisulphatide antibody ELISAs in about 20000 serum samples that were referred to the Neuromuscular Clinical Laboratory, Washington University, St Louis from 1990 to the end of 1994. We found 112 serum samples with high titre selective IgM antibody binding to sulphatide $(>4500)$. These serum samples had no binding to myelin associated glycoprotein (MAG) by ELISA or western blot analysis, and levels of IgM binding to GM1, asialo-GM1, and GD1b gangliosides and to histone $\mathrm{H} 3$ that were less than $25 \%$ of the antisulphatide titre. ${ }^{7}$ Detailed histories and neurological examinations and testing for a serum $\mathbf{M}$ protein (by either immunoelectrophoresis or immunofixation) were available for 23 of these patients. Twenty of the 23 patients were evaluated by 
one of us. The three remaining patients were evaluated as part of one of our previous studies. $^{8}$

\section{ELECTROPHYSIOLOGICAL DATA}

Patients were studied by standard techniques with surface temperatures above $30^{\circ} \mathrm{C}$ in the legs and $32^{\circ} \mathrm{C}$ in the arms. Results were classified as demyelinating, axonal, or normal, using standard criteria. Demyelinating neuropathies met three of four criteria including slowed nerve conduction velocities, prolonged terminal latency, prolonged minimal $F$ wave latency, or conduction block. ${ }^{9}$ Electrodiagnostic studies were classified as axonal if there were reduced sensory or motor nerve action potential amplitudes with conduction velocities $>70 \%$ of the lower limit of normal. ${ }^{10}$ Studies were also classified as axonal if there were motor abnormalities suggestive of a neuropathy, but no features of demyelination as outlined above.

\section{IMMUNOCYTOCHEMISTRY}

Serum IgM binding to human peripheral nerve was evaluated using rapidly frozen sural nerve biopsies and tissue obtained at necropsy. When 10 initial comparisons showed that patterns of IgM binding to both preparations were identical, we used necropsied nerve for the remainder of the study. Frozen sections of nerve $(8 \mu \mathrm{m})$ were placed on glass slides, dried overnight, fixed with acetone $\left(-20^{\circ} \mathrm{C}\right.$ for 20 minutes), and blocked with $100 \%$ normal goat serum (NGS) for one to two hours. To evaluate IgM binding, tissues were incubated with patient serum (diluted $1: 100$ in $10 \%$ NGS; final volume $100 \mu \mathrm{l}$ ) at $4^{\circ} \mathrm{C}$ overnight in a humidity chamber, washed in phosphate buffered saline (PBS), pH $7 \cdot 2 \times 3$, incubated with peroxidase conjugated goat antihuman IgM (1:200) for four hours at room temperature, washed again with PBS $\times 3$, and developed with $0.05 \%$ diaminobenzidine and $0.01 \% \mathrm{H}_{2} \mathrm{O}_{2}$ in PBS. Patterns of IgM binding were evaluated by a blinded observer without prior knowledge of the results of serum testing. Light microscopic images were captured digitally using PAX-it! (Midwest Information Systems) computer software and then printed directly on to glossy paper.

\section{ELISA ANTIBODY ASSAY}

Serum was assayed for $\kappa$ or $\lambda$ light chain binding to sulphatide by ELISA methodology as previously described. ${ }^{3}$ Briefly, $500 \mathrm{ng}$ sulphatide, dissolved in $15 \mu \mathrm{l}$ methanol was added to wells and evaporated to dryness. Remaining binding sites were blocked with $100 \mu 11 \%$ human serum albumin in PBS for four hours at room temperature. Plates were then washed three times with $1 \%$ bovine serum albumin (BSA) in PBS. Subsequent steps were performed at $4^{\circ} \mathrm{C}$. Between steps, washing $(x 3)$ was performed using PBS with $1 \%$ BSA. Serum samples were tested by adding dilutions (1:3000 to $1: 300000$ in PBS with $1 \% \mathrm{BSA}$ ) to wells overnight. The binding of light chains was measured using four hour exposure to goat antihuman $\kappa$ or $\lambda$ light chains linked to horseradish peroxidase (Organon Teknika-Cappel, West Chester, PA) in PBS with 1\% BSA (1:20 000). Colour was developed with $100 \mu \mathrm{l}$ substrate buffer $(0 \cdot 1 \mathrm{M}$ citrate buffer, $\mathrm{pH} 4.5$, with $0.004 \% \mathrm{H}_{2} \mathrm{O}_{2}$ and $0 \cdot 1 \%$ phenylenediamine) for 30 minutes. Optical density (OD) was determined at $450 \mathrm{~nm}$. A serum antibody with a titre of $x$ was detectable ( $>0.05$ OD units over controls) up to a dilution of at least $1 / \mathbf{x}$.

\section{STATISTICS}

Comparisons between groups were made using Fisher's exact or rank sum tests.

\section{Results}

\section{CLINICAL CHARACTERISTICS}

Nineteen of the 23 patients (83\%) with high titres $(>4500)$ of serum IgM binding to sulphatide had clinical syndromes consistent with chronic sensory, or sensory-motor neuropathies. Eight of these 19 patients had no other historical or laboratory findings to suggest an aetiology for the polyneuropathy. Nine patients had serum $M$ proteins, eight of the IgM isotype, and one IgA detected by immunofixation or immunoelectrophoresis. Only two patients had other disorders that commonly cause polyneuropathy: diabetes (one) and a history of alcohol misuse (one). Patients with an $\mathbf{M}$ protein were not significantly older than those without an $M$ protein at the time of onset of symptoms or at presentation to a neurologist (table 1). There was also no significant difference in the sex distribution between the two groups. The four patients without chronic sensory neuropathy had Guillain-Barré syndrome (one), lower motor neuron syndromes (weakness was asymmetric and predominantly distal; two), and dermatomyositis (one).

All 19 patients with polyneuropathies had sensory symptoms and signs in distal limbs (table 2). Many (79\%) noted symptoms of numbness or paraesthesiae. Pain and dysaesthesiae were more common $(P=0.006)$ in patients without $(80 \%)$ than in those with (11\%) an $M$ protein. Most patients (89\%) had loss of both small and large fibre sensory modalities. Reduced or absent deep tendon reflexes tended to be more common ( $P=$ $0.06)$ in patients with (89\%) than in those without $(40 \%)$ an $M$ protein. Weakness was found in $53 \%$ of the patients. It was more common in those with $(78 \%)$ than in those without (30\%) a serum $M$ protein, but the difference did not quite reach significance $(P=$ $0.07)$. Gait disorders, due to sensory ataxia or weakness, were present in $53 \%$ of patients.

\section{SERUM ANTIBODY TESTING}

Serum samples with an $M$ protein detected during the clinical evaluation had significantly higher titres $(P=0.01)$ of IgM binding to sulphatide (mean $=193400$ ), than did those without an $M$ protein (mean = 19030 ; table 1). Testing by ELISA for light chain reactivity disclosed that the antisulphatide antibodies were monoclonal in six of the nine serum sam- 
Table 1 Clinical and laboratory features in individual patients with polyneuropathy and serum IgM anti-sulphatide antibodies with and without an $M$ protein

\begin{tabular}{|c|c|c|c|c|c|}
\hline Patient & $A g e^{\star} / \operatorname{sex}$ & $M$ protein & $\begin{array}{l}\text { EMG/NCS } \\
\text { Pattern }\end{array}$ & Immunocytochemistryt & $\begin{array}{l}\text { Titre of IgM } \\
\text { v sulphatide }\end{array}$ \\
\hline 1 & $76 / \mathrm{F}$ & IgMk & NAf & Myelin & 651200 \\
\hline 2 & $56 / \mathrm{M}$ & IgM $\kappa$ & Dem & Axons & 74600 \\
\hline 3 & $50 / \mathrm{M}$ & IgMк & Dem & Negative & 6210 \\
\hline 4 & $71 / \mathrm{M}$ & $\operatorname{Ig} A \lambda$ & NA $\ddagger$ & Myelin, axons & 17280 \\
\hline 5 & $70 / \mathrm{M}$ & IgMk & NA $\ddagger$ & Myelin & 300500 \\
\hline 6 & $60 / M$ & IgM & Dem & Negative & 505000 \\
\hline 7 & $82 / \mathrm{F}$ & IgM & Dem & Endoneurium & 37890 \\
\hline 8 & $64 / M$ & IgMK & NA & Endoneurial & 48000 \\
\hline 9 & $67 / F$ & IgMk & $\mathrm{N} \pi$ & $\begin{array}{l}\text { Endoneurial } \\
\text { macrophages }\end{array}$ & 100000 \\
\hline 10 & $66 / F$ & - & $\mathrm{Ax}$ & Axons & 5790 \\
\hline 11 & $40 / F$ & - & $\mathrm{Ax}$ & $\begin{array}{l}\text { Axons, endoneurial } \\
\text { macrophages }\end{array}$ & 4570 \\
\hline 12 & $58 / \mathrm{M}$ & - & $A \mathbf{x}$ & $\begin{array}{l}\text { Axons, endoneurial } \\
\text { macrophages }\end{array}$ & 5150 \\
\hline 13 & $65 / F$ & - & NAS & Axons & 56420 \\
\hline 14 & $66 / M$ & - & $\mathrm{Ax}$ & Axons & 6870 \\
\hline 15 & $58 / F$ & - & $\mathrm{Ax}$ & Axons & 9450 \\
\hline 16 & $63 / \mathrm{F}$ & - & $\mathbf{N}$ & Axons & 10050 \\
\hline 17 & $67 / \mathrm{F}$ & - & $A x$ & $\begin{array}{l}\text { Axons, endoneurial } \\
\text { macrophages }\end{array}$ & 38000 \\
\hline 18 & 63/M & - & $\mathrm{Ax}$ & Negative & 36000 \\
\hline 19 & $43 / \mathrm{F}$ & - & $\mathbf{N}$ & Axons & 18000 \\
\hline
\end{tabular}

*Age at time of symptom onset.

fImmunocytochemistry refers to the major structures stained by patient serum IgM. Note that serum IgM from some patients stained two structures.

$\neq$ Detailed electrodiagnostic information was not available, but information from the chart review suggested a demyelinating neuropathy.

Detailed electrodiagnostic information was not available, but information from the chart review suggested an axonal neuropathy.

Abnormal quantitative sensory testing.

$\mathrm{NA}=$ not available, Dem $=$ demyelinating, $\mathrm{Ax}=$ axonal, $\mathrm{N}=$ normal

ples with an $\mathbf{M}$ protein. In five, antisulphatide antibodies were of the $\kappa$ light chain class and in one of the $\lambda$ class. In one serum sample, antisulphatide antibody binding was predominantly composed of $\kappa$ light chains, but a low titre of $\lambda$ chain binding was also present. In the two remaining samples, one of which had an IgA $M$ protein, antisulphatide antibody binding was equal for $\kappa$ and $\lambda$ light chains. The type of antisulphatide antibody light chain detected by ELISA was identical to the reported $M$ protein light chain detected on immunofixation or immunoelectrophoresis in those serum samples in which light chain binding was predominantly one class. In the 10 serum samples with no $M$ protein, titres of antisulphatide binding were generally similar for $\kappa$ and $\lambda$ light chain classes. No serum had IgM binding to MAG when tested by ELISA or western blot. Two of the serum samples with immunocytochemical binding to myelin (see below) were tested for, and had no binding to, sulphated glucuronyl paragloboside.

Table 2 Summary of features in patients with polyneuropaty and serum IgM antisulphatide antibodies with and without an $M$ protein

\begin{tabular}{|c|c|c|}
\hline & $\begin{array}{l}\text { No M protein } \\
(n(\%))\end{array}$ & $\begin{array}{l}M \text { protein } \\
(n(\%))\end{array}$ \\
\hline $\begin{array}{l}\text { Clinical characteristics: } \\
\text { Paraesthesiae } \\
\text { Numbness } \\
\text { Dysaesthesiae and pain } \\
\text { Distal sensory loss }\end{array}$ & $\begin{array}{l}(\mathrm{n}=10) \\
4(40) \\
8(80) \\
8(80)\end{array}$ & $\begin{array}{l}(\mathrm{n}=9) \\
5(55) \\
7(78) \\
1(11)\end{array}$ \\
\hline $\begin{array}{l}\text { Large fibre } \\
\text { Small fibre } \\
\text { Reflexes decreased or absent } \uparrow \\
\text { Gait ataxia } \\
\text { Weakness } \ddagger \\
\text { Electrodiagnostic features } \\
\text { Demyelination } \S \\
\text { Small CMAP amplitudes }\rceil \\
\text { Immunocytochemistry } \\
\text { Serum IgM binding to axons } \oint \\
\text { Serum IgM binding to myelin }\end{array}$ & $\begin{array}{l}9(90) \\
9(90) \\
4(40) \\
4(40) \\
3(30) \\
(\mathrm{n}=9) \\
0(0) \\
1(11) \\
(\mathrm{n}=10) \\
9(90) \\
0(0)\end{array}$ & $\begin{array}{l}9(100) \\
8(80) \\
8(89) \\
6(67) \\
7(78) \\
(n=5) \\
4(80) \\
4(80) \\
(n=9) \\
2(22) \\
3(33)\end{array}$ \\
\hline
\end{tabular}

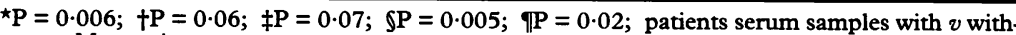
out an $M$ protein.
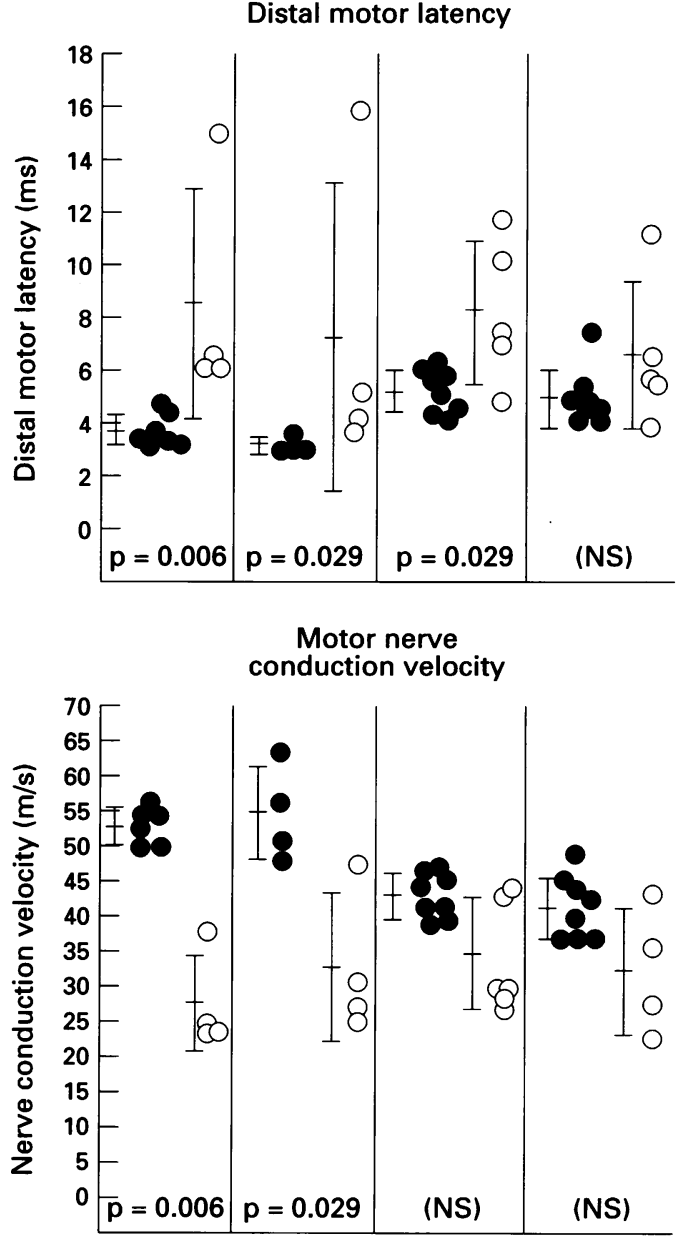

Compound muscle action potential amplitude

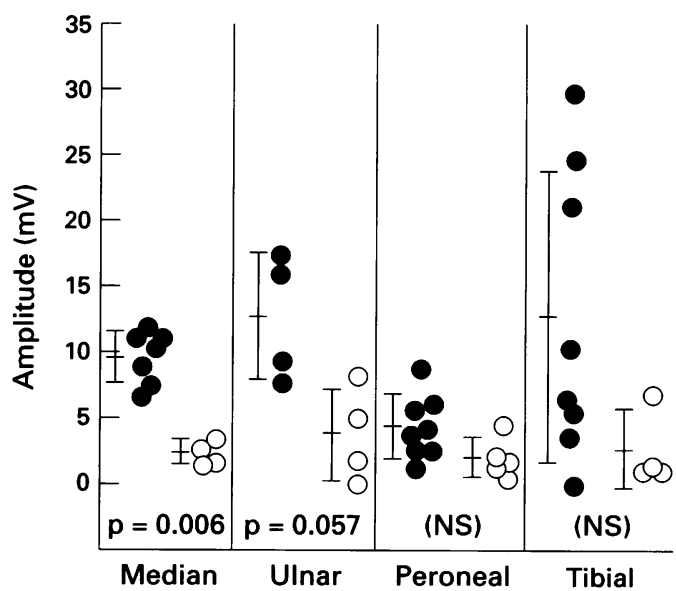

Figure 1 Results of electrodiagnostic studies on patients with antisulphatide antibodies and polyneuropathy syndromes. Open circles represent patients with an $M$ protein and closed circles represent patients without an $M$ protein. Not all nerves were studied in all 14 patients. Compound muscle action potential amplitudes $<0.1 \mathrm{mV}$ were not included in the analysis. Error bars are mean (SD).

\section{ELECTROPHYSIOLOGY}

Detailed electrodiagnostic examinations, performed by one of the authors, including at least two motor and two sensory nerves were available on 14 of the 19 patients with polyneuropathy and clinical and serum data. Eleven of the 14 patients had definite evidence of polyneuropathies on electrodiagnostic studies (tables 1 and 2). Four were classified as demyelinating 
Figure 2 Typical patterns of peripheral nerve immunostaining by serum IgM (diluted 1:100). (A) IgM from patient No 19 (No M protein; antisulphatide titre: $18000)$ stained axons (arrow) in peripheral nerve. This pattern of staining was seen in nine out of 10 patients without an $M$ protein $(\times 1000)$. (B) IgM from patient No 1 (IgM M protein; antisulphatide titre: 651 200) stained peripheral nerve myelin, primarily the inner and outer lamellae (arrows). This was the most common pattern of serum binding from those serum samples with an $M$ protein, seen in three out of seven serum samples that stained peripheral nerve (× 1000). (C) IgM from a control patient (IgM M protein; no sulphatide binding) did not stain axons or myelin $(\times 1000)$.

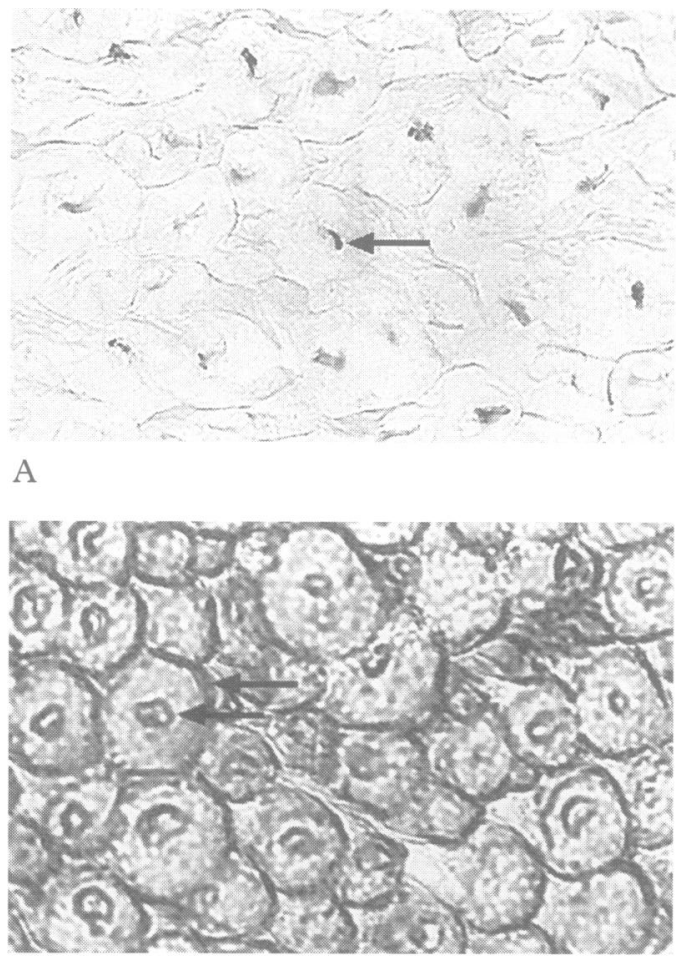

B

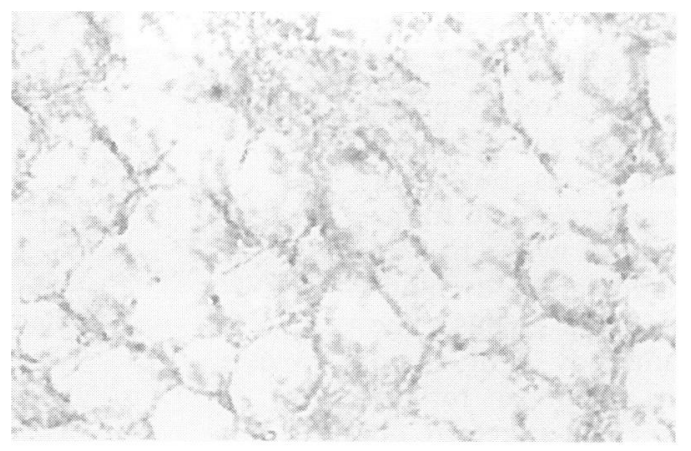

C

and seven axonal. Three patients had normal routine electrodiagnostic studies, but one had abnormal results on quantitative sensory testing. The four patients with a demyelinating neuropathy all had a serum $M$ protein detected during the clinical evaluation. Four other patients, with characterisation of their neuropathy as demyelinating on summaries of electrodiagnostic testing, but without available primary data, also all had a serum $M$ protein. By contrast, only one of 10 patients with no electrodiagnostic evidence of demyelination had an $M$ protein $(\mathbf{P}=0.005 v$ the demyelinating group).

Quantitative analysis of the electrodiagnostic data showed similar results (fig 1). In all nerves, mean motor conduction velocities were slower in patients with than in those without an $M$ protein. For example, velocities were 27 (SD 7) $\mathrm{m} / \mathrm{s}$ compared with $53(\mathrm{SD} \mathrm{2}) \mathrm{m} / \mathrm{s}$ for the median nerve $(P=0.006)$ and $33(S D 10) \mathrm{m} / \mathrm{s}$ compared with 55 (SD 7) $\mathrm{m} / \mathrm{s}$ for the ulnar nerve $(P=0.029)$. Similarly, mean distal motor latencies were longer in patients with an $M$ protein, with significance for the median, ulnar, and deep peroneal nerves.

Measurements of compound muscle action potential (CMAP) amplitudes correlated with the trend toward more weakness in patients with a serum $M$ protein (fig 1 ). In the median nerve the average CMAP amplitude was $2 \cdot 5$ (SD 0.9 ) $\mathrm{mV}$ in patients with an $M$ protein, only $26 \%$ of the 9.7 (SD 2.0 ) $\mathrm{mV}$ value in patients without $M$-proteins $(P=0.006)$. In the ulnar nerve, the average CMAP amplitude was only 4.0 (SD 3.5 ) $\mathrm{mV}$ in patients with an $\mathrm{M}$ protein, $31 \%$ of the $12 \cdot 8$ (SD $4 \cdot 8) \mathrm{mV}$ value in those without an $M$ protein $(P=0 \cdot 06)$.

IMMUNOCYTOCHEMISTRY OF PERIPHERAL NERVE (TABLES 1 AND 2, FIG 2)

Serum IgM from patients without an $M$ protein consistently stained peripheral nerve axons (nine of $10 ; 90 \%$; Fig 2A). One serum sample showed no IgM binding to peripheral nerve structures. Three of the nine serum samples also stained endoneurial macrophages.

Serum IgM from patients with an $M$ protein less commonly stained axons (two of nine; $22 \% ; P=0.005)$. Serum IgM from six patients with an $M$ protein stained other neural structures, including myelin (three; fig 2B), endoneurial macrophages (two), and endoneurial connective tissue (one). One serum sample stained both myelin and axons. Two samples had no IgM binding to peripheral nerve. Serum IgM from nine control samples from patients without peripheral neuropathy, including four with IgM $M$ proteins but no binding to sulphatide, showed no significant peripheral nerve staining (fig 2C).

\section{Discussion and conclusions}

Our results show that high titres $(>4500)$ of serum IgM antisulphatide antibodies are commonly associated with polyneuropathy syndromes having a prominent sensory component. Nineteen of 23 patients $(83 \%)$ had sensory or sensory-motor neuropathy syndromes. Our data allow a rough estimate of the frequency of specific high titre IgM antisulphatide antibodies in patients with polyneuropathy. In our overall series we found 112 serum samples with high titre selective IgM antibody binding to sulphatide ( $>4500)$. Using the data from this study, an $83 \%$ specificity estimates that 93 serum samples were from patients with sensory or sensory-motor neuropathies. Of the 20000 samples tested, about 13000 were referred for evaluation of sensory neuropathy related antigens. Thus the frequency of IgM antisulphatide antibodies at titres that have specificity for patients with sensory or sensory-motor polyneuropathies $(>4500)$ is likely to be about $0.7 \%(93 / 13$ $000)$. We previously estimated that titres of antisulphatide antibodies $(>1500)$ that are out of the range of normal might occur in up to $20 \%$ to $30 \%$ of patients with sensory or sensory-motor neuropathies. ${ }^{3}$ The current figure is lower because: (1) only antibody titres greater than 4500 were considered in this study, (2) this survey evaluated the clinical correlations of IgM but not IgG antisulphatide antibodies, and (3) polyreactive antisulphatide serum samples (those with IgM binding to a range of glycol- 
ipids in addition to sulphatide) were excluded from consideration.

The clinical and pathological features of antisulphatide antibody associated neuropathies fell into two subgroups according to whether or not a serum $M$ protein was present. Patients with antisulphatide antibodies but no serum $M$ protein typically had axonal, predominantly sensory, syndromes with dysaesthesiae. The pain was disabling in several patients. It could be diffuse or proximal, as well as distal. Weakness was never severe, and only present in a minority of patients. Sensory loss usually involved both large and small fibre modalities, including pain and vibration. Deep tendon reflexes were often preserved even at the ankles. Electrodiagnostic studies showed normal nerve conduction velocities. Reduced amplitudes of sensory nerve action potentials were the predominant abnormality in most studies.

The axonal features of the neuropathy on electrodiagnostic testing correlated with the presence of serum antibodies directed against axons in peripheral nerve. Serum samples from nine of the 10 patients without an $M$ protein showed IgM binding to axons. Blocking experiments suggest that the antisulphatide antibodies are responsible for the binding to axons (G Lopate, unpublished data). However, it is unclear whether the antigenic target on axons is sulphatide, or a structurally similar molecule such as another sulphated glycolipid or glycoprotein. $^{1211}$

The second group of patients, with both antisulphatide antibodies and serum $\operatorname{IgM} M$ proteins, had prominent motor involvement with significantly smaller CMAP amplitudes on electrodiagnostic testing, and a trend toward more frequent weakness on examination. Weakness was predominantly distal, but in severe cases involved proximal muscles as well. Sensory loss involved both large and small fibre modalities, but, by contrast with patients without an $\mathbf{M}$ protein, pain was rarely a prominent complaint. Deep tendon reflexes were often absent, even at proximal sites.

Demyelinating features were common on electrodiagnostic studies of patients with both antisulphatide antibodies and serum IgM $M$ proteins. They were present in $80 \%$ of those tested. Prolonged distal latencies and slowed nerve conduction velocities that did not vary greatly from nerve to nerve were the most striking demyelinating feature on electrodiagnostic studies. Conduction block was rarely present. This pattern of electrodiagnostic abnormalities, prolonged distal latencies, and slow conduction velocities without conduction block, is more similar to that found in anti-MAG neuropathies, than to abnormalities in chronic immune demyelinating polyneuropathy. ${ }^{12-15}$ The electrodiagnostic studies of patients with antisulphatide antibodies but no serum $M$ proteins were significantly different, with no demyelinating features in any of the nine (table 2).

Some patients with demyelinating features on electrodiagnostic testing had serum IgM binding to peripheral nerve myelin and
Schwann cell cytoplasm. However, in several others, serum IgM bound predominantly to endoneurial cells, endoneurium, or axons. The antigenic targets for the IgM in antisulphatide serum samples, that predispose to axonal loss or demyelination in peripheral nerve, remain to be defined. The different patterns of immunostaining of peripheral nerve by serum samples with antisulphatide antibodies suggest that tissue binding of these antibodies is likely to be determined by cross reactivity with other antigens or subfractions of sulphatide. Both axons and myelin contain sulphatide and various other glycoproteins and glycolipids with sulphated sugar moieties. ${ }^{11} 1617$ Other results from our laboratory show that IgM antisulphatide autoantibodies vary greatly in their ability to bind to sulphatide subfractions that vary in the structure and degree of hydroxylation of their lipid moiety. Differences in the range of binding of IgM to such antigenic targets could determine whether the primary focus of an antisulphatide antibody related polyneuropathy is axonal or demyelinating.

1 Ilyas AA, Cook SD, Dalakas MC, Mithen FA. Anti-MAG IgM paraproteins from some patients with polyneuropathy associated with IgM paraproteinemia also react with sulfatide. F Neuroimmunol 1992;37:85-92.

2 Nemni R, Fazio R, Quattrini A, Lorenzetti I, Mamoli D, Canal N. Antibodies to sulfatide and to chondroitin sulfate $\mathrm{C}$ in patients with chronic sensory neuropathy. $\mathcal{F}$ Neuroimmunol 1993;43:79-85.

3 Pestronk A, Li F, Griffin J, et al. Polyneuropathy syndromes associated with serum antibodies to sulfatide and myelinassociated glycoprotein. Neurology 1991;41:357-62.

4 Nobile-Orazio E, Manfredini E, Carpo M, et al. Frequency and clinical correlates of anti-neural IgM antibodies in neuropathy associated with IgM monoclonal gammopathy. Ann Neurol 1994;36:416-24.

5 van den Berg LH, Lankamp CLAM, de Jager AEJ, et al. Anti-sulphatide antibodies in peripheral neuropathy. $f$ Anti-sulphatide antibodies in peripheral neur
Neurol Neurosurg Psychiatry 1993;56:1164-8.

6 Quattrini A, Corbo M, Dhaliwal SK, et al. Anti-sulfatide antibodies in neurological disease: binding to rat dorsal root ganglia neurons. $\mathcal{F}$ Neurol Sci 1992;112:152-9.

7 Pestronk A, Li F, Bieser K, et al. Anti-MAG antibodies: major effects of antigen purity and antibody cross-reactivity on ELISA results and clinical correlation. Neurology 1994 44:1131-7.

8 Pestronk A, Choksi R, Bieser K, Goldstein JM, Adler $\mathrm{CH}$, Caselli RJG, George EB. Treatable gait disorder and polyneuropathy associated with high titer serum IgM binding to antigens that copurify with myelin-associated glycoproto antigens that copurify with myelin-
tein. Muscle Nerve 1994;17:1293-300.

9 Anonymous. Research criteria for diagnosis of chronic inflammatory demyelinating polyneuropathy (CIDP). Report from an Ad Hoc Subcommittee of the American Report from an Ad Hoc Subcommittee of the American
Academy of Neurology AIDS Task Force [review]. Neurology 1991;41:617-8

10 Daube JR. Application of clinical neurophysiology: assessing symptom complexes. In: Daube JR, ed. Clinical neurophysiology. Philadelphia: FA Davis, 1996:473-98.

11 Fredman P, Lycke J, Andersen O, Vrethem M, Ernerudh J, Svennerholm L. Peripheral neuropathy associated with monoclonal IgM antibody to glycolipids with a terminal glucuronyl-3-sulfate epitope. $₹$ Neurol 1993;240:381-7.

12 Kaku DA, England JD, Sumner AJ. Distal accentuation of conduction slowing in polyneuropathy associated with antibodies to myelin-associated glycoprotein and sulantibodies to myelin-associated glycoprotein and sul-
phated glucuronyl paragloboside. Brain 1994;117:941-7.

13 Kelly J, Jr. The electrodiagnostic findings in polyneuropathies associated with IgM monoclonal gammopathies. Muscle Nerve 1990;13:1113-7.

14 Lewis RA, Sumner AJ. The electrodiagnostic distinctions between chronic familial and acquired demyelinative neuropathies. Neurology 1982;32:592-6.

15 Simmons Z, Albers JW, Bromberg MB, Feldman EL Presentation and initial clinical course in patients with chronic inflammatory demyelinating polyradiculoneuropathy: comparison of patients without and with monoclonal gammopathy. Neurology 1993;43:2202-9.

16 Svennerholm L, Bostrom K, Fredman P, Jungbjer B, Mansson JE, Rynmark BM. Membrane lipids of human peripheral nerve and spinal cord. Biochem Biophys Acta 1992;1128:1-7.

17 Hammer JA, O'Shannessy DJ, De Leon M, Gould R, Zand $\mathrm{D}$, Daune GQ, Quarles RH. Immunoreactivity of PMP$22, \mathrm{P0}$, and other 19 to $28 \mathrm{kDa}$ glycoproteins in peripheral nerve myelin of mammals and fish with HNK1 and related antibodies. $\mathcal{F}$ Neurosci Res 1993;35:546-58. 